\title{
Chapter 22 \\ New Developments in the Management of Nasopharyngeal Carcinoma
}

\author{
Xiaoshuang Niu and Yungan Tao
}

\section{Unique Characteristics of Nasopharyngeal Carcinoma}

Nasopharyngeal carcinoma (NPC) is an epithelial carcinoma with a specific geographic distribution. It affected an estimated 129,000 patients worldwide in 2018, with the highest incidences are in regions in Southeast Asia (especially in South China), and North Africa [1].

NPC is categorized into three pathological subtypes on the basis of WHO criteria. Differentiated tumours with surface keratin are defined as type I, whereas types II and III refer to non-keratinising differentiated and undifferentiated tumours, respectively. Types II and III were combined into a single category of nonkeratinising carcinoma which constitutes most cases in endemic areas (>95\%) [2]. EBV infection, host genetics, environmental factors and other factors are contributors in the occurrence and development of NPC. Among them, EBV infection may be the most common cause of NPC [3]. The nasopharynx is anatomically concealed, and it is adjacent to important organs such as brainstem, optic nerve and optic chiasm. NPC is prone to early retropharyngeal and cervical lymph node metastasis and local skull base invasion. More than $70 \%$ of NPC receive a diagnosis of locoregionally advanced (LA) disease at presentation. Distant metastasis predominates as the pattern of disease relapse, which accounts for approximately $70 \%$ of patients with cancer-specific mortality [4]. Radiotherapy (RT) is the cornerstone of initial treatment due to its radiosensitive characteristic and deep-seated location. Given the

\footnotetext{
X. Niu

Department of Radiation Oncology, Fudan University Shanghai Cancer Center, Shanghai, China

Department of Oncology, Shanghai Medical College, Fudan University, Shanghai, China

Y. Tao $(\bowtie)$

Department of Radiation Oncology, Institut Gustave Roussy, Villejuif, France

e-mail: yungan.tao@gustaveroussy.fr
} 
depth and complex location of the nasopharynx, surgery is especially used as a rescue method for regional lymph node failure, while with limited use for local recurrence.

\section{Radiotherapy}

Radiotherapy is the main treatment for non-metastatic NPC. The technology of photon-based RT has developed from two-dimensional radiotherapy (2D-RT), three-dimensional conformal radiotherapy (3D-CRT) to Intensity modulated radiotherapy (IMRT). IMRT is the standard RT technique compared with 2D/3D RT and could reduce late toxicities such as xerostomia. Overall survival (OS) and tumor control could potentially be enhanced by the improved dosimetric properties. In a monocenter randomized trial [5], the 5-year OS rate was 79.6\% for the IMRT group and $67.1 \%$ for the 2D-RT group $(\mathrm{p}=0.001)$. Patients in IMRT group had significantly lower radiation-induced toxicities than those in 2D-RT group. Pow et al. [6] compared directly the effect of IMRT vs. 2D-RT on salivary flow in patients with early-stage NPC. Fifty-one patients with T2N0/N1 NPC were enrolled in a randomized controlled clinical study and received IMRT or 2D-RT. The result showed that IMRT was significantly better than 3D-CRT in terms of parotid sparing for earlystage disease. Results from a similar phase 3 trial of the Groupe D'Oncologie Radiothérapie Tête et Cou (GORTEC trial 2004-01) have been reported in ESMO 2018 by Tao et al. [7], in which IMRT improved significantly xerostomia compared with conformal radiotherapy in locoregionally advanced head and neck squamous cell carcinoma (LA-HNSCC).

Along with the RT technique improvements, precisely defining the target volume and adjacent organs at risk (OARs) has become crucial for a good treatment outcome. Target delineation in NPC often proves challenging because of the notoriously narrow therapeutic margin. High doses are needed to achieve optimal levels of tumor control, despite the apparent radio-sensitivity of the tumor in many patients [8]. We established the international guideline for the delineation of the Clinical Target Volume (CTV) of NPC. This set of consensus guidelines has been developed to provide a practical reference for appropriate contouring to ensure optimal target coverage [8]. Even in the contemporary era of IMRT with extensive use of concurrent chemotherapy, the dosimetric inadequacy enforced by dose constraints on OARs remains one of the most important independent factors affecting treatment outcome. It is often difficult to achieve the optimal balance and trade-off between risks of local recurrence owing to inadequate tumor coverage versus potential serious late complications [9]. A guideline was developed to provide a practical reference for setting dose prioritization and acceptance criteria for tumor volumes and OARs [9]. Both of these two guidelines provided useful references for NPC radiation management. The final decision on the treatment volumes and treatment prescription should be based on the individual clinical situation and the patient's acceptance of optimal balance of risk $[8,9]$. 
Chen and colleagues [10] reported the role of RT in addition to systemic therapy for initially diagnosed metastatic NPC in ESMO 2019. Between April 2014, and August 2018, 173 patients were assessed for eligibility, of whom 126 patients with a complete response (CR) or partial response (PR) after 3 cycles of cisplatin and fluorouracil were randomised (63 patients in the chemo-radiotherapy group and 63 in the chemotherapy group). The median follow-up was 26.7 months. The researchers found that the addition of RT to chemotherapy alone significantly improved OS (hazard ratio [HR] 0.42, 95\% CI 0.23-0.77, $\mathrm{p}=0.004$ ) and progression free survival (PFS) (hazard ratio [HR] 0.36, 95\% CI 0.23-0.57, p < 0.001) for metastatic NPC patients who obtained objective response after chemotherapy.

There are still several remaining questions: Firstly, in order to reduce the late toxicities, we still need to define the best dose/volume after induction chemotherapy because NPC patients are often young and with long-term survival. Secondly, for stage II NPC patients, whether the IMRT alone could be used instead of the combination of chemo-radiotherapy especially for those patients with T1-T2N0 or N1 with only a single small neck lymph node. Finally, although IMRT is currently the preferred method, there is great interest in using proton or carbon ion RT to further improve the treatment rate of NPC. Compared with IMRT, intensity-modulated proton therapy (IMPT) and intensity-modulated carbon ion therapy (IMCT) have a dosimetric advantage in NPC and better protection for normal tissues [11]. Studies with proton therapy (NCT00592501) and carbon ion therapy (NCT02569788) are under way to provide more information about the application of IMPT and IMCT in NPC.

\section{Chemotherapy and Radiotherapy Combinations}

The combination of RT and chemotherapy is the key development in the treatment of LA diseases. A large number of trials have shown that concurrent chemoradiotherapy (CCRT) had a survival advantage compared with RT alone for NPC [4, 12, 13]. The meta-analysis MAC-NPC (Meta-Analysis of Chemotherapy in Nasopharynx Carcinoma) including eight trials with 1753 patients demonstrated an absolute survival benefit of $6 \%$ at 5 years from the addition of chemotherapy (from $56 \%$ to $62 \%)$. The most significant benefit of chemotherapy on OS was CCRT [14]. In the recent actualization of MAC-NPC meta-analysis including 19 trials and 4806 patients, we confirmed that the addition of chemotherapy to RT significantly improved OS (hazard ratio [HR] 0.79, 95\% CI 0.73-0.86, p < 0.0001; absolute benefit at 5 years $6.3 \%, 95 \%$ CI 3.5-9.1). The most significant benefits of chemotherapy on OS were seen with either CCRT plus adjuvant chemotherapy (HR 0.65 [95\% CI 0.56-0.76]) or CCRT alone (0.80 [0.70-0.93]) [15].

However, it is still controversial whether adjuvant chemotherapy after CCRT can bring more survival benefits. A phase 3 multicenter randomized controlled trial in 508 patients with stage III-IV NPC did not show a significant improvement in failure-free survival when the combination of cisplatin and 5-FU (PF regimen) was 
given after CCRT (with weekly cisplatin $40 \mathrm{mg} / \mathrm{m}^{2}$ ) [16]. Long-term follow-up data confirmed these findings [17]. More recently, the network meta-analysis based on the MAC-NPC data has shown that the addition of adjuvant chemotherapy to CCRT achieved the highest survival benefit and consistent improvement for all end points. However, the addition of induction chemotherapy to concurrent chemo-radiotherapy achieved the highest effect on distant control [18]. These results should be considered with caution because the comparisons in the network meta-analysis were indirect.

Compared with adjuvant chemotherapy, induction chemotherapy may be a promising treatment strategy for NPC due to better tolerance and a stronger effect on micro-metastasis. Several phase 3 trials have shown benefit of induction chemotherapy when added to cisplatin-based CCRT. An early-closed French multicenter phase 3 trial (GORTEC 2006-02) including 86 French/Tunisian patients with stage II-IV NPC showed that 3 cycles of induction chemotherapy with docetaxelcisplatin-5-FU (the TPF schedule) significantly improved 3-year PFS (hazard ratio $(\mathrm{HR})=0.44 ; 95 \%$ confidence interval $(\mathrm{CI}): 0.20-0.97, \mathrm{P}=0.042)$ compared to CCRT (with weekly cisplatin $40 \mathrm{mg} / \mathrm{m}^{2}$ ) alone. Similarly, the 3 years OS rate was $86.3 \%$ in the TPF arm versus $68.9 \%$ in the reference arm (HR $=0.40 ; 95 \% \mathrm{CI}$ : $0.15-1.04, \mathrm{P}=0.05)$. The tolerance of TPF schedule was quite good with $95 \%$ of patients who completed 3 cycles [19]. A large-scale Chinese multicenter phase 3 trial has been reported, that confirmed these data. In that study, comprising 480 patients with stages III-IVB NPC (except T3-4N0), they made use of modified TPF dose schedule and used high-dose cisplatin $\left(100 \mathrm{mg} / \mathrm{m}^{2}\right.$ q 3 weeks $)$ during CCRT. Induction with TPF significantly improved 5-year OS and failure-free survival [20]. More recently, Zhang et al. compared gemcitabine and cisplatin (the socalled GP schedule) as induction chemotherapy plus CCRT with CCRT alone in 480 Chinese patients with stage III to IVb NPC (N1-3). The 3-year recurrence-free survival was $85.3 \%$ in the induction chemotherapy group and $76.5 \%$ in the standardtherapy group (stratified hazard ratio for recurrence or death, $0.51 ; 95 \%$ confidence interval $[\mathrm{CI}], 0.34$ to $0.77 ; \mathrm{P}=0.001$ ). $\mathrm{OS}$ at 3 years was $94.6 \%$ and $90.3 \%$, respectively (stratified hazard ratio for death, $0.43 ; 95 \% \mathrm{CI}, 0.24$ to 0.77 ) [21]. The induction chemotherapy with the GP schedule was better tolerated in Chinese patients (96.7\% of patients with 3 cycles) than the dose-reduced TPF schedule in the previous study (88\% tolerated 3 cycles) and therefore could potentially be used more widely (Table 22.1).

Several other phase 3 trials of chemoradiotherapy combinations in LA-NPC are in progress to answer several unresolved issues in NPC. What is the best strategy in combination with platinum-based CCRT, induction chemotherapy or adjuvant chemotherapy? Can we delete the chemotherapy during RT by using induction first, followed by RT and then adjuvant chemotherapy? What are the less toxic drugs combined with radiotherapy? The gemcitabine/cisplatin regimen as an induction regimen plus CCRT is being tested with RT plus gemcitabine and cisplatin as adjuvant chemotherapy (NCT03366415). Replacing cisplatin with nedaplatin, or fluorouracil with capecitabine during induction and concurrent phases may reduce toxicities and improve quality of life (NCT03503136). 
Table 22.1 Randomised trials evaluating induction chemotherapy plus concurrent chemoradiotherapy vs. concurrent chemoradiotherapy alone

\begin{tabular}{|c|c|c|c|c|c|}
\hline & Experimental chemotherapy & $\begin{array}{l}\text { Control } \\
\text { chemotherapy }\end{array}$ & $\begin{array}{l}\text { Sample } \\
\text { size }\end{array}$ & $\begin{array}{l}\text { Overall } \\
\text { survival }\end{array}$ & $\begin{array}{l}\text { Progression- } \\
\text { free survival }\end{array}$ \\
\hline $\begin{array}{l}\text { Frikha } \\
\text { et al. } \\
{[19]}\end{array}$ & $\begin{array}{l}\text { Induction: Docetaxel } \\
75 \mathrm{mg} / \mathrm{m}^{2} \mathrm{~d} 1 \text {; cisplatin } \\
75 \mathrm{mg} / \mathrm{m}^{2} \mathrm{~d} 1 \text {; fluorouracil } \\
750 \mathrm{mg} / \mathrm{m}^{2} \mathrm{~d} 1-5 \\
\text { q3weeks } \times 3 \text {; concurrent: } \\
\text { Cisplatin } 40 \mathrm{mg} / \mathrm{m}^{2} \mathrm{~d} 1 \text {; } \\
\text { q1week } \times 7\end{array}$ & $\begin{array}{l}\text { Concurrent: } \\
\text { Cisplatin } 40 \mathrm{mg} / \\
\mathrm{m}^{2} \mathrm{~d} 1 ; \\
\mathrm{q} 1 \text { week } \times 7\end{array}$ & 83 & $\begin{array}{l}86 \% \text { vs. } \\
69 \% \\
\text { (3 year } \\
\text { results) } \\
\mathrm{p}=0.059\end{array}$ & $\begin{array}{l}74 \% \text { vs. } 57 \% \\
(3 \text { year } \\
\text { results }) \\
p=0.042\end{array}$ \\
\hline $\begin{array}{l}\text { Sun } \\
\text { et al. } \\
{[20]}\end{array}$ & $\begin{array}{l}\text { Induction: Docetaxel } \\
60 \mathrm{mg} / \mathrm{m}^{2} \mathrm{~d} 1 \text {; cisplatin } \\
60 \mathrm{mg} / \mathrm{m}^{2} \mathrm{~d} 1 \text {; fluorouracil } \\
600 \mathrm{mg} / \mathrm{m}^{2} \mathrm{~d} 1-5 ; \\
\text { q3weeks } \times 3 \text {; concurrent: } \\
\text { Cisplatin } 100 \mathrm{mg} / \mathrm{m}^{2} \mathrm{~d} 1 \text {; } \\
\text { q3week } \times 3\end{array}$ & $\begin{array}{l}\text { Concurrent: } \\
\text { Cisplatin } 100 \mathrm{mg} / \\
\mathrm{m}^{2} \mathrm{~d} 1 ; \\
\mathrm{q} 3 \text { weeks } \times 3\end{array}$ & 480 & $\begin{array}{l}86 \% \text { vs. } \\
78 \% \\
(5 \text { year } \\
\text { results) } \\
p=0.042\end{array}$ & $\begin{array}{l}77 \% \text { vs. } 66 \% \\
(5 \text { year } \\
\text { results }) \\
p=0.019\end{array}$ \\
\hline $\begin{array}{l}\text { Zhang } \\
\text { et al. } \\
{[21]}\end{array}$ & $\begin{array}{l}\text { Induction: Gemcitabine } 1 \mathrm{~g} / \\
\mathrm{m}^{2} \mathrm{~d} 1,8 ; \text { cisplatin } 80 \mathrm{mg} / \mathrm{m}^{2} \\
\mathrm{~d} 1 ; \mathrm{q} 3 \text { weeks } \times 3 ; \\
\text { concurrent: Cisplatin } \\
100 \mathrm{mg} / \mathrm{m}^{2} \mathrm{~d} 1 ; \text { q3week } \times 3\end{array}$ & $\begin{array}{l}\text { Concurrent: } \\
\text { Cisplatin } 100 \mathrm{mg} / \\
\mathrm{m}^{2} \mathrm{~d} 1 ; \\
\mathrm{q} 3 \text { weeks } \times 3\end{array}$ & 480 & $\begin{array}{l}94.6 \% \text { vs } \\
90.3 \% \\
\text { (3 year } \\
\text { results) }\end{array}$ & $\begin{array}{l}85.3 \% \text { vs. } \\
76.5 \% \text { ( } 3 \text { year } \\
\text { results) } \\
p=0.002\end{array}$ \\
\hline
\end{tabular}

\section{EBV-DNA}

Plasma Epstein-Barr virus (EBV) DNA is an independent prognostic biomarker for NPC $[22,23]$. Quantification of plasma EBV DNA is useful for monitoring patients with NPC and predicting the outcome of treatment [24]. Chan and colleagues compared adjuvant chemotherapy against clinical observation for patients with high risk of recurrence based on EBV DNA after completing RT or chemoradiotherapy in a phase 3 trial. In 789 enrolled patients at the completion of chemoradiotherapy, 216 patients with detectable EBV DNA after radiotherapy, 104 patients were randomized to adjuvant GP schedule or observation. They found that the level of post-RT plasma EBV DNA correlated significantly with the hazards of loco-regional failure, distant metastasis, and death. However, no significant difference was found in 5 -year relapse-free survival rate between the two arms $(49.3 \%$ vs. $54.7 \%$; $\mathrm{P}=0.75$; hazard ratio for relapse or death, 1.09; 95\% CI, 0.63 to 1.89) [25]. The ongoing NRG-HN001 trial also uses plasma EBV DNA to identify patients with NPC at a higher risk of relapse for adjuvant chemotherapy. The purpose was to establish whether adjuvant gemcitabine and paclitaxel is better than cisplatin and fluorouracil for patients with detectable EBV DNA, and whether adjuvant cisplatin and fluorouracil can be omitted in patients with undetectable plasma EBV DNA. Lv et al. quantified circulating EBV DNA copy number in 673 NPC patients undergoing radical induction chemotherapy and chemo-radiotherapy. The patients divided into four prognostic phenotypes (early responders, intermediate responders, late responders, and treatment resistant) that were correlated with efficacy of 
chemotherapy intensity. Based on the exploratory observations, it was proposed a risk stratified treatment adaptation design that is based on the phenotypic clusters and longitudinal surveillance of cell free EBV DNA. Real-time monitoring of EBV DNA response added prognostic information and had the potential utility for riskadapted treatment de-intensification/intensification in NPC [26].

\section{Immunotherapy and Chemoradiotherapy}

Recently, immune checkpoint blocking therapy has made a breakthrough in cancer treatment. In NPC clinical histological samples, it is characterised by high PD-L1 expression (up to $90 \%$ of tumour cells) and abundant infiltration of non-malignant lymphocytes [27, 28]. This nature makes NPC patients potentially suitable for immunotherapy treatment [29]. Fang and colleagues reported the results of two single-arm, phase 1 trials. Camrelizumab (an anti-PD-1 monoclonal antibody) was used as (1) monotherapy in 93 patients with pre-treated recurrent or metastatic disease, and (2) in combination with gemcitabine plus cisplatin in 23 first-line patients. Overall response was 34\% in the monotherapy trial and $91 \%$ in the combination trial. One year PFS was $27 \%$ and $61 \%$ in the two arms, respectively. The combination of camrelizumab plus gemcitabine and cisplatin has promising preliminary anti-tumour activity for treatment-naive loco-regionally recurrent or metastatic disease [30]. Several randomized phase 3 trials in NPC patients are ongoing due to promising anti-tumour activity and predictable safety profile of anti-PD-1/PD-L1 therapy. One phase 2 trial (NCT03925090) is assessing neoadjuvant and adjuvant toripalimab (anti PD-1) combined with CCRT in NPC. Two phase 3 trials (NCT03700476 and NCT03427827) are investigating induction and concurrent sintilimab or adjuvant camrelizumab in LA-NPC. These studies will be evaluating the value of adding anti-PD-1 therapy to standard treatment (CCRT or GP-CCRT) in locally advanced NPC.

\section{Conclusions}

Nasopharyngeal carcinomas have unique characteristics with a specific geographic distribution and IMRT is the standard radiotherapy technique. Concurrent chemoradiotherapy is a standard of care in NPC (especially N0-1) and induction chemotherapy plus chemo-radiotherapy in stage III/IV N1-3. The benefit of RT in addition to systemic therapy has been shown for the initially diagnosed metastatic NPC. Furthermore, ongoing studies will identify adjuvant chemotherapy according to EBV DNA and the role of immunotherapy in association with chemoradiotherapy. 


\section{References}

1. Bray F, Ferlay J, Soerjomataram I, Siegel RL, Torre LA, Jemal A. Global cancer statistics 2018: GLOBOCAN estimates of incidence and mortality worldwide for 36 cancers in 185 countries. CA Cancer J Clin. 2018;68(6):394-424.

2. Chua M, Wee J, Hui EP, Chan A. Nasopharyngeal carcinoma. Lancet. 2016;387(10022):1012-24.

3. Chan K, Woo J, King A, Zee B, Lam W, Chan SL, et al. Analysis of plasma Epstein-Barr virus DNA to screen for nasopharyngeal cancer. N Engl J Med. 2017;377(6):513-22.

4. Lee AW, Ng WT, Chan LL, Hung WM, Chan CC, Sze HC, et al. Evolution of treatment for nasopharyngeal cancer-success and setback in the intensity-modulated radiotherapy era. Radiother Oncol. 2014;110(3):377-84.

5. Peng G, Wang T, Yang KY, Zhang S, Zhang T, Li Q, et al. A prospective, randomized study comparing outcomes and toxicities of intensity-modulated radiotherapy vs. conventional twodimensional radiotherapy for the treatment of nasopharyngeal carcinoma. Radiother Oncol. 2012;104(3):286-93.

6. Pow EH, Kwong DL, McMillan AS, Wong MC, Sham JS, Leung LH, et al. Xerostomia and quality of life after intensity-modulated radiotherapy vs. conventional radiotherapy for earlystage nasopharyngeal carcinoma: initial report on a randomized controlled clinical trial. Int $\mathrm{J}$ Radiat Oncol Biol Phys. 2006;66(4):981-91.

7. Tao Y, Auperin A, Blanchard P, Alfonsi M, Sun XS, Rives M, et al. Concurrent cisplatin and dose escalation with intensity-modulated radiotherapy (IMRT) versus conventional radiotherapy for locally advanced head and neck squamous cell carcinomas (HNSCC): GORTEC 2004-01 randomized phase III trial. Radiother Oncol. 2020;150:18-25.

8. Lee AW, Ng WT, Pan JJ, Poh SS, Ahn YC, AlHussain H, et al. International guideline for the delineation of the clinical target volumes (CTV) for nasopharyngeal carcinoma. Radiother Oncol. 2018;126(1):25-36.

9. Lee AW, Ng WT, Pan JJ, Chiang CL, Poh SS, Choi HC, et al. International guideline on dose prioritization and acceptance criteria in radiation therapy planning for nasopharyngeal carcinoma. Int J Radiat Oncol Biol Phys. 2019;105(3):567-80.

10. Chen M, You R, You-Ping L, Huang P, Zou X, Shen G, Zhang H. Chemotherapy plus localregional radiotherapy versus chemotherapy alone in primary metastatic nasopharyngeal carcinoma: a randomized, open-label, phase 3 trial. Ann Oncol. 2019;30(Suppl 5):v449-74. https:// doi.org/10.1093/annonc/mdz252.

11. Lewis GD, Holliday EB, Kocak-Uzel E, Hernandez M, Garden AS, Rosenthal DI, et al. Intensity-modulated proton therapy for nasopharyngeal carcinoma: decreased radiation dose to normal structures and encouraging clinical outcomes. Head Neck. 2016;38(Suppl 1):E1886-95.

12. Al-Sarraf M, LeBlanc M, Giri PG, Fu KK, Cooper J, Vuong T, et al. Chemoradiotherapy versus radiotherapy in patients with advanced nasopharyngeal cancer: phase III randomized Intergroup study 0099. J Clin Oncol. 1998;16(4):1310-7.

13. Wee J, Tan EH, Tai BC, Wong HB, Leong SS, Tan T, et al. Randomized trial of radiotherapy versus concurrent chemoradiotherapy followed by adjuvant chemotherapy in patients with American Joint Committee on Cancer/International Union against cancer stage III and IV nasopharyngeal cancer of the endemic variety. J Clin Oncol. 2005;23(27):6730-8.

14. Baujat B, Audry H, Bourhis J, Chan AT, Onat H, Chua DT, et al. Chemotherapy in locally advanced nasopharyngeal carcinoma: an individual patient data meta-analysis of eight randomized trials and 1753 patients. Int J Radiat Oncol Biol Phys. 2006;64(1):47-56.

15. Blanchard P, Lee A, Marguet S, Leclercq J, Ng WT, Ma J, et al. Chemotherapy and radiotherapy in nasopharyngeal carcinoma: an update of the MAC-NPC meta-analysis. Lancet Oncol. 2015;16(6):645-55.

16. Chen L, Hu CS, Chen XZ, Hu GQ, Cheng ZB, Sun Y, et al. Concurrent chemoradiotherapy plus adjuvant chemotherapy versus concurrent chemoradiotherapy alone in patients with 
locoregionally advanced nasopharyngeal carcinoma: a phase 3 multicentre randomised controlled trial. Lancet Oncol. 2012;13(2):163-71.

17. Chen L, Hu CS, Chen XZ, Hu GQ, Cheng ZB, Sun Y, et al. Adjuvant chemotherapy in patients with locoregionally advanced nasopharyngeal carcinoma: long-term results of a phase 3 multicentre randomised controlled trial. Eur J Cancer. 2017;75:150-8.

18. Ribassin-Majed L, Marguet S, Lee A, Ng WT, Ma J, Chan A, et al. What is the best treatment of locally advanced nasopharyngeal carcinoma? An individual patient data network metaanalysis. J Clin Oncol. 2017;35(5):498-505.

19. Frikha M, Auperin A, Tao Y, Elloumi F, Toumi N, Blanchard P, et al. A randomized trial of induction docetaxel-cisplatin-5FU followed by concomitant cisplatin-RT versus concomitant cisplatin-RT in nasopharyngeal carcinoma (GORTEC 2006-02). Ann Oncol. 2018;29(3):731-6.

20. Sun Y, Li WF, Chen NY, Zhang N, Hu GQ, Xie FY, et al. Induction chemotherapy plus concurrent chemoradiotherapy versus concurrent chemoradiotherapy alone in locoregionally advanced nasopharyngeal carcinoma: a phase 3 , multicentre, randomised controlled trial. Lancet Oncol. 2016;17(11):1509-20.

21. Zhang Y, Chen L, Hu GQ, Zhang N, Zhu XD, Yang KY, et al. Gemcitabine and cisplatin induction chemotherapy in nasopharyngeal carcinoma. N Engl J Med. 2019;381(12):1124-35.

22. Lo YM, Chan AT, Chan LY, Leung SF, Lam CW, Huang DP, et al. Molecular prognostication of nasopharyngeal carcinoma by quantitative analysis of circulating Epstein-Barr virus DNA. Cancer Res. 2000;60(24):6878-81.

23. Kim KY, Le QT, Yom SS, Pinsky BA, Bratman SV, Ng RH, et al. Current state of PCR-based Epstein-Barr virus DNA testing for nasopharyngeal cancer. J Natl Cancer Inst. 2017;109(4).

24. Lin JC, Wang WY, Chen KY, Wei YH, Liang WM, Jan JS, et al. Quantification of plasma Epstein-Barr virus DNA in patients with advanced nasopharyngeal carcinoma. N Engl J Med. 2004;350(24):2461-70.

25. Chan A, Hui EP, Ngan R, Tung SY, Cheng A, Ng WT, et al. Analysis of plasma Epstein-Barr virus DNA in nasopharyngeal cancer after chemoradiation to identify high-risk patients for adjuvant chemotherapy: a randomized controlled trial. J Clin Oncol. 2018:O2018777847.

26. Lv J, Chen Y, Zhou G, Qi Z, Tan K, Wang H, et al. Liquid biopsy tracking during sequential chemo-radiotherapy identifies distinct prognostic phenotypes in nasopharyngeal carcinoma. Nat Commun. 2019;10(1):3941.

27. Zhu Q, Cai MY, Chen CL, Hu H, Lin HX, Li M, et al. Tumor cells PD-L1 expression as a favorable prognosis factor in nasopharyngeal carcinoma patients with pre-existing intratumorinfiltrating lymphocytes. Oncoimmunology. 2017;6(5):e1312240.

28. Larbcharoensub N, Mahaprom K, Jiarpinitnun C, Trachu N, Tubthong N, Pattaranutaporn $\mathrm{P}$, et al. Characterization of PD-L1 and PD-1 expression and CD8+ tumor-infiltrating lymphocyte in Epstein-Barr virus-associated nasopharyngeal carcinoma. Am J Clin Oncol. 2018;41(12):1204-10.

29. Zhang J, Fang W, Qin T, Yang Y, Hong S, Liang W, et al. Co-expression of PD-1 and PD-L1 predicts poor outcome in nasopharyngeal carcinoma. Med Oncol. 2015;32(3):86.

30. Fang W, Yang Y, Ma Y, Hong S, Lin L, He X, et al. Camrelizumab (SHR-1210) alone or in combination with gemcitabine plus cisplatin for nasopharyngeal carcinoma: results from two single-arm, phase 1 trials. Lancet Oncol. 2018;19(10):1338-50. 
Open Access This chapter is licensed under the terms of the Creative Commons Attribution 4.0 International License (http://creativecommons.org/licenses/by/4.0/), which permits use, sharing, adaptation, distribution and reproduction in any medium or format, as long as you give appropriate credit to the original author(s) and the source, provide a link to the Creative Commons license and indicate if changes were made.

The images or other third party material in this chapter are included in the chapter's Creative Commons license, unless indicated otherwise in a credit line to the material. If material is not included in the chapter's Creative Commons license and your intended use is not permitted by statutory regulation or exceeds the permitted use, you will need to obtain permission directly from the copyright holder. 